IP Periodica Polytechnica Chemical Engineering

62(1), pp. 32-42, 2018

https://doi.org/10.3311/PPch.10913

Creative Commons Attribution (i)

RESEARCH ARTICLE

\section{Effect of Cyclic Butylene Terephthalate Oligomer on the Properties of Styrene- Butadiene and Acrylonitrile-Butadiene Rubbers}

\author{
István Zoltán Halász ${ }^{1}$, Tamás Bárány ${ }^{1,2^{*}}$
}

Received 21 April 2017; accepted after revision 17 August 2017

\begin{abstract}
In this work the effect of cyclic butylene terephthalate (CBT) was studied on the curing, rheological, morphological and mechanical properties of styrene butadiene rubber (SBR), oil extended styrene butadiene rubber (oSBR), acrylonitrile butadiene rubbers (NBR) with various acrylonitrile (AN) content and a carboxylated acrylonitrile butadiene rubber (XNBR). The effect of CBT on the oil resistance of the NBR and XNBR based compounds was also investigated. Viscosities of the uncured compounds were significantly decreased by CBT and it also acted as a semi-active filler, effectively reinforcing the tested rubbers, therefore it is suggested to be a bifunctional additive for tested rubbers. CBT also showed to have a positive effect on the oil resistance of NBR compounds.
\end{abstract}

\section{Keywords}

nitrile rubber, styrene-butadiene bifunctional additive, cyclic butylene terephthalate oligomer, CBT, plasticizer, processing aid, semi-active filler

\footnotetext{
${ }^{1}$ Department of Polymer Engineering, Faculty of Mechanical Engineering, Budapest University of Technology and Economics,

H-1111 Budapest, Müegyetem rkp. 3., Hungary

${ }^{2}$ MTA-BME Research Group for Composite Science and Technology,

H-1111 Budapest, Müegyetem rkp. 3., Hungary

*Corresponding author, e-mail: barany@pt.bme.hu
}

\section{Introduction}

Properties of rubbers can be tailored upon requirements for a wide range of application fields. Their ability to withstand large deformation both under compression and tension without cracking and their damping capability are those specific features which are exploited in products' design. However, these noteworthy and outstanding properties over plastics are accompanied by some drawbacks, such as complex compound formulations and complicated processing. A wide variety of rubbers and additives are used in rubber industry to adjust the performance of compounds to meet given specifications. Further, the effects of certain additives are adverse to those of others. Therefore, to reach balanced properties (e.g. mechanical behaviour, wear resistance, processability) is a very challenging task. Cured unfilled synthetic rubbers show poor mechanical and wear properties, therefore various fillers (usually inorganic mineral fillers and carbon black) - among others - are incorporated into the recipes. Regrettably, these fillers significantly increase the viscosity of the rubber mixtures, thereby hampering their processability. In order to compensate this issue various types of processing aids and plasticizers are used. However, usually they have a negative effect on the mechanical properties. The application of an additive lacking this opposing effect would have great research potential. Our research strategy was to find an additive which is able to reduce the viscosity of the uncured compounds significantly and works as reinforcement in the cured rubber.

Cyclic butylene terephthalate oligomer (CBT) is a cyclic oligoester that polymerizes in situ in the presence of suitable catalysts at high temperatures $\left(>140^{\circ} \mathrm{C}\right)$ via ring-opening polymerization $[1,2]$. This makes $\mathrm{CBT}$ a suitable matrix material of various micro- $[3,4]$ and nanocomposites $[5,6]$. Further advantage of CBT as a matrix material for composites is linked with its very low melt viscosity, which facilitates the appropriate impregnation of the reinforcing structure. However, the polymerized cyclic butylene terephthalate (pCBT) is more brittle than conventional polybutylene terephthalate (PBT) produced by polycondensation. This is caused by the fact that pCBT exhibits higher molecular weight and crystallinity than PBT. 
Several techniques can be found in the literature for the compensation of this embrittlement, for example co-polymerization with $\varepsilon$-caprolactone [7], compounding with polycaprolactone, polycarbonate, polytetrahydrofurane, multiwalled carbon nanotubes [8], chain extending by a bifunctional epoxy resin during the polymerization [9], or reactive blending with isocyanates $[10,11]$. Most of these toughening techniques lead to a drop in the crystallinity of the resulting $\mathrm{pCBT}$, which decreases the brittleness of it. CBT has very low melt viscosity (about $30 \mathrm{mPas}$ at $190^{\circ} \mathrm{C}$ ) and it does not affect the mechanical properties of the neat thermoplastic polymers negatively if used as processing aid. It is proven to be an excellent processing aid for thermoplastic resins and a suitable carrier for various masterbatches $[12,13]$.

Thus, CBT may possibly lower the viscosity of rubber mixes, as well. Moreover, in the follow-up cooling phase after vulcanization CBT recrystallizes and forms a separate disperse phase in the rubber matrix. This may be associated with reinforcing effect because the CBT crystals themselves may have large aspect ratios (prism-, and plate like crystals). As a consequence, $\mathrm{CBT}$ is a promising candidate for the dual action viscosity reduction/reinforcement, as initially quoted by the group of Karger-Kocsis [14-16].

Up to now, only a few papers were devoted to investigate CBT-rubber blends. In peroxide cured HNBR rubbers [14-16] the introduced CBT recrystallized during cooling and formed plate-like CBT crystals in the rubber matrix and significantly improved the mechanical properties of HNBR. Attempt was also made to polymerize $\mathrm{CBT}$ to $\mathrm{pCBT}$ during the curing process of the HNBR. The pCBT conversion remained, however, very low (ca. $11 \%$ after $25 \mathrm{~min}$ at $190^{\circ} \mathrm{C}$ ). A subsequent annealing at $250^{\circ} \mathrm{C}$ for 3 hours increased the conversion rate to $70-90 \%$ [14]. Different wear tests showed that both CBT and pCBT remarkably decreased the specific wear rate and the coefficient of friction of the related compounds $[15,16]$. Our previous work showed that CBT has a similar effect in other rubber compounds, such as styrene-butadiene (SBR), acrylonitrile-butadiene (NBR) and ethylene-propylene-diene (EPDM) [17]. This work is devoted to study the effect of unpolymerizable CBT variant (i.e. without a catalyst) on the rheological, mechanical and morphological properties of SBR, oil-extended SBR (oSBR) and NBR compounds (former works [14-16] were focused on the polymerizable variant of CBT in HNBR rubber). The NBR rubbers selected contained various acrylonitrile (AN) contents and even a carboxylated NBR (XNBR) was involved in this work. Our intention with their selection was to get a clear picture on how the rubber polarity, including carboxylation, influence the above listed properties. Compounds were made with CBT contents of $0,10,20,30,40,50 \mathrm{phr}$ for SBR, oSBR and NBR 39, and with 0 and 20 phr CBT content for the NBR 18, NBR 32,5X and NBR 34. SBR and oSBR are widely used in the rubber industry, therefore it is desirable to investigate the effect of a new additive in a relatively wide content scale. Among NBR based compounds NBR 39 showed the most promising result, which led to the broadening of the CBT contents of the tested NBR 39 based rubbers.

\section{Materials and processing}

Properties of the rubbers used for compounding are given in Table 1.

Table 1 Rubber types, producers and properties

\begin{tabular}{|c|c|c|}
\hline Abbreviation & Producer, Type & Properties \\
\hline SBR & $\begin{array}{l}\text { Goodyear } \\
\text { Chemical, } \\
\text { Plioflex }^{\circledR} 1502\end{array}$ & $\begin{array}{l}\left.\text { Mooney viscosity (ML, } 1+4,100^{\circ} \mathrm{C}\right): 44 \\
\text { Bound styrene content: } 23.5 \mathrm{~m} \%\end{array}$ \\
\hline oSBR & $\begin{array}{l}\text { Styron, Buna }{ }^{\circledR} \\
\text { SB } 1723\end{array}$ & $\begin{array}{l}\left.\text { Mooney viscosity (ML, } 1+4,100^{\circ} \mathrm{C}\right): 50 \\
\text { Bound styrene content: } 23.5 \mathrm{~m} \%\end{array}$ \\
\hline NBR 18 & $\begin{array}{l}\text { Lanxess, } \\
\text { Perbunan }^{\circledR} \\
1846 \mathrm{~F}\end{array}$ & $\begin{array}{l}\text { Mooney viscosity }\left(\mathrm{UML}, 1+4,100^{\circ} \mathrm{C}\right) \text { : } \\
45 \pm 5 \\
\text { Bound acrylonitrile content: } 18 \pm 1 \mathrm{~m} \%\end{array}$ \\
\hline NBR $32.5 \mathrm{X}$ & $\begin{array}{l}\text { Lanxess, } \\
\text { Krynac }^{\circledR} \\
\text { X146 }\end{array}$ & $\begin{array}{l}\text { Mooney viscosity }\left(\mathrm{UML}, 1+4,100^{\circ} \mathrm{C}\right) \text { : } \\
45 \pm 5 \\
\text { Bound acrylonitrile content: } 32.5 \pm 1.5 \mathrm{~m} \%\end{array}$ \\
\hline NBR 34 & $\begin{array}{l}\text { Lanxess, } \\
\text { Perbunan }^{\circledR} \\
3445 \mathrm{~F}\end{array}$ & $\begin{array}{l}\left.\text { Mooney viscosity (UML, } 1+4,100^{\circ} \mathrm{C}\right) \text { : } \\
45 \pm 5 \\
\text { Bound acrylonitrile content: } 34 \pm 1 \mathrm{~m} \%\end{array}$ \\
\hline NBR 39 & $\begin{array}{l}\text { Lanxess, } \\
\text { Perbunan }^{\circledR} \\
3945 \mathrm{~F}\end{array}$ & $\begin{array}{l}\text { Mooney viscosity (UML, } 1+4,100^{\circ} \mathrm{C} \text { ): } \\
45 \pm 5 \\
\text { Bound acrylonitrile content: } 39 \pm 1 \mathrm{~m} \%\end{array}$ \\
\hline
\end{tabular}

The oligomer was CBT $100^{\circledR}$, produced by Cyclics Europe $\mathrm{GmbH}$ (Schwarzheide, Germany). The other ingredients used were: zinc-oxide ( $\mathrm{ZnO} 500$, provided by Zinc Oxide LLC, Dickson, Tennesse, USA), stearic acid (Radiacid 0444, product of Oleon, Ertvelde, Belgium). N-cyclohexyl-2-benzothiazole sulfenamide (CBS) and sulphur were purchased from Ningbo Actmix Polymer (Ningbo, China) under the trade names of Curekind CBS and Curekind Sulphur, respectively.

Formulations of the tested rubbers are listed in Table 2.

Table 2 Recipes of the compounds. Note: phr - parts per hundred parts rubber *0-50 phr CBT content for SBR and NBR 39, **0, $20 \mathrm{phr}$ CBT content for NBR 18, NBR 32.5X and NBR 34

\begin{tabular}{lll}
\hline & oSBR & $\begin{array}{l}\text { SBR, NBR 18, NBR 32.5X, } \\
\text { NBR 34, NBR 39 }\end{array}$ \\
\cline { 2 - 3 } & phr & \\
\hline Rubber & 137.5 & 100 \\
ZnO & 5 & 5 \\
Stearic acid & 1 & 1 \\
CBS & 1 & 1 \\
Sulfur & 2 & 2 \\
\hline CBT & $0,10,20,30$, & $0,10,20,30,40,50 *$ and \\
& 40,50 & $0,20 * *$ \\
\hline
\end{tabular}


Compounding occurred on a laboratory two-roll mill (Labtech LRM-SC-110, Labtech Engineering Co.Ltd. Samutprakarn, Thailand) at roll temperatures of $70^{\circ} \mathrm{C}$ and $50^{\circ} \mathrm{C}$ (front and rear, respectively), and friction of 1.3.

The compositional difference among oSBR and other rubbers is due to the fact that the formers contained $37.5 \mathrm{phr}$ extender oil (accordingly, the neat rubber content of $137.5 \mathrm{phr}$ oSBR was $100 \mathrm{phr}$ SBR).

Curing into sheets with $2 \mathrm{~mm}$ thickness occurred at $170^{\circ} \mathrm{C}$ under 2 MPa pressure in a Collin Teach-Line Platen Press 200E laboratory press (Dr. Collin GmbH, Ebersberg, Germany). Curing times $\left(\mathrm{t}_{0,9}\right.$ - time corresponding to $90 \%$ curing) were determined from the vulcameter curves. The vulcanized sheets were cooled in air without pressure at a cooling rate of ca. $50^{\circ} \mathrm{C} / \mathrm{min}$.

\section{Testing methods}

\subsection{Curing tests}

Curing properties were studied with a MonTech Monsanto R100S rheometer (MonTech Werkstoffprüfmaschinen $\mathrm{GmbH}$, Buchen, Germany) in isothermal $\left(\mathrm{T}=170^{\circ} \mathrm{C}\right)$ time sweep mode (1.667 Hz, $3^{\circ}$ angle) for $45 \mathrm{~min}$.

\subsection{Viscosity tests}

Absolute values of the complex viscosities of the uncured compounds (i.e. without sulphuric curatives) were measured using a TA AR 2000 parallel plate rheometer (TA Instruments, New Castle, Delaware, USA), at $170^{\circ} \mathrm{C}$ with a sinusoidal oscillation. The strain amplitude and oscillation frequency were set for 25 and $40 \mathrm{rad} / \mathrm{s}$, respectively. The gap was $1.5 \mathrm{~mm}$ between the parallel plates. The duration of the tests was $3 \mathrm{~min}$, and the actual values were recorded in every $3 \mathrm{~s}$. Values from the $2^{\text {nd }}$ and $3^{\text {rd }}$ min were averaged and standard deviation was also calculated.

\subsection{Tensile and tear tests}

Tensile tests were performed on a Zwick Z250 universal testing machine equipped with a $20 \mathrm{kN}$ load cell (Zwick GmbH, Ulm, Germany). Type 1 specimens of DIN 53504 standard with a clamping length of $60 \mathrm{~mm}$ were loaded at $500 \mathrm{~mm} / \mathrm{min}$ crosshead speed. Tear tests were made on the same testing machine and test speed by the ASTM D624 standard (Type C specimen), with a clamping length of $56 \mathrm{~mm}$. Both tests were run at room temperature.

\subsection{Hardness tests}

Hardness tests were carried out on the prepared sheets with ten parallel measurements on each material by DIN 53505 standard. A Zwick H04.3150 hardness tester (Zwick GmbH, Ulm, Germany) was used with Shore A head using $12.5 \mathrm{~N}$ load.

\subsection{DMTA tests}

Dynamic mechanical properties of the rubber blends in the absence of CBT and at the highest CBT content (50 phr at SBR, oSBR and NBR 39 and 20 phr at NBR 18, NBR 32.5X and NBR 34) were investigated using a TA Q800 DMTA machine (TA Instruments, New Castle, Delaware, USA) in tensile mode on rectangle specimens with dimension of ca. $2 \times 2.5 \times 10$ (thickness $\mathrm{x}$ width $\mathrm{x}$ clamped length) $\mathrm{mm}$. Tests were run between -100 and $100^{\circ} \mathrm{C}$ with $3{ }^{\circ} \mathrm{C} / \mathrm{min}$ heating rate at $10 \mathrm{~Hz}$ frequency with $0.01 \mathrm{~N}$ preload, and superimposed $0.01 \%$ sinusoidal strain.

\subsection{Scanning electron microscopy (SEM)}

In order to observe the morphology of the related rubbers SEM images were taken from the fracture surfaces of the tensile specimens. SEM images were taken using a Jeol JSM6380LA (Jeol LTD., Tokyo, Japan). The observed surfaces were sputter-coated with gold.

\subsection{Oil resistance tests}

Oil resistance tests were carried out on NBR based compounds by following the ASTM D471-98 standard. Three specimens of each compound with a dimensions of ca. $25 \times 50 \times 2 \mathrm{~mm}^{3}$ were cut from the cured sheets and immersed in ASTM oil (No. 3) for 70 hours at room temperature. The specimens were weighed before the immersion and right after the take out, then the change in mass was calculated.

\section{Results and discussion}

\subsection{Curing properties}

Curing properties are listed in Table 3. The maximum and the minimum values of measured torque decreased with increasing CBT content confirming the viscosity reduction effect of this oligomer. SBR and oSBR compounds with increasing CBT content exhibited slightly lower $\mathrm{t}_{0.1}$ and $\mathrm{t}_{0.5}$, but higher $\mathrm{t}_{0.9}$ values. This suggests that CBT slightly shortens the induction phase of curing but decreases the curing speed. In NBR-based compounds no induction phase shortening was found, each cure time parameter showed a slight increment in the presence of CBT. The explanation of this is presumably a "diluting" effect of the CBT, causing a reduction in the relative amount of the curatives compared to the rubber. The reduction of the induction phase in SBR and oSBR compounds suggests that some alteration of the curing reaction is present, which may be the topic of further research.

\subsection{Viscosity}

Results of the viscosity tests are shown in Fig. 1. One can see that the absolute values of the complex viscosities significantly decreased for all tested rubber mixes. So, CBT can effectively enhance the processability of these rubber compounds. This effect was less pronounced at CBT contents above $30 \mathrm{phr}$ in SBR and oSBR (cf. Fig. 1a), and above $20 \mathrm{phr}$ in NBR 39 compounds (cf. Fig. 1b). 


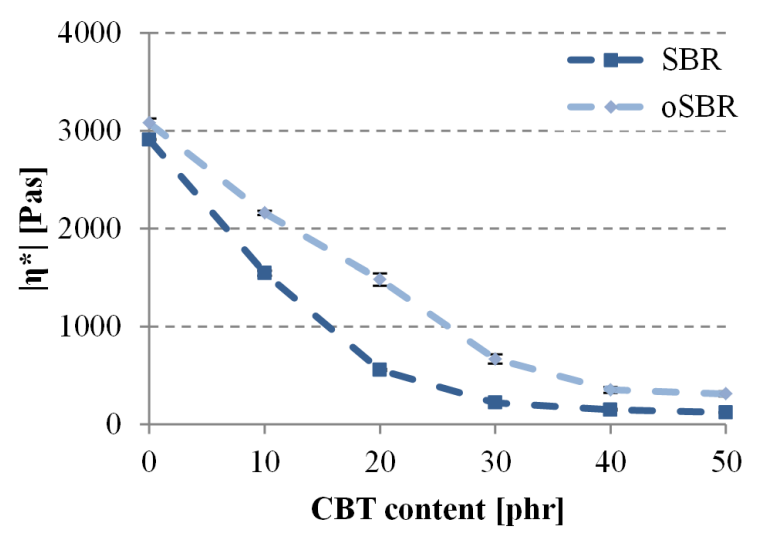

a)

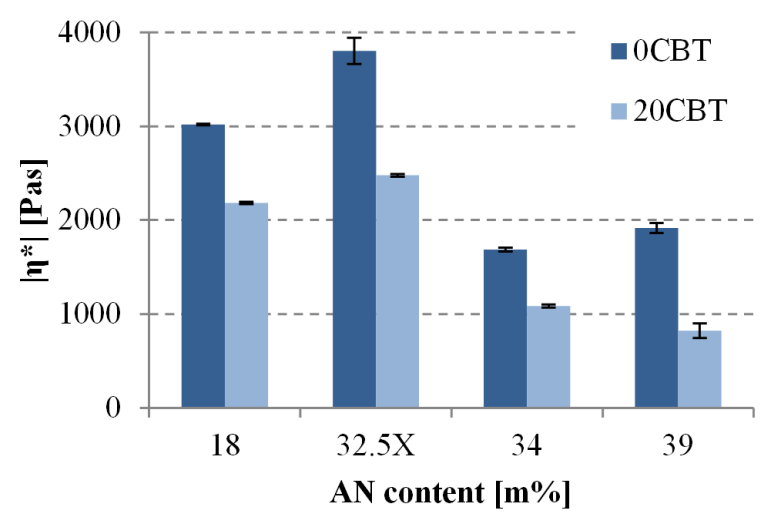

b)

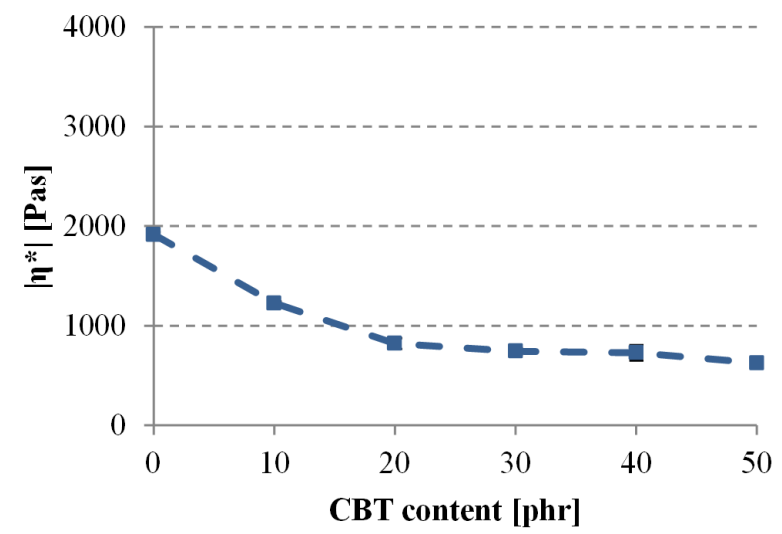

c)

Fig. 1 Viscosities of the uncured compounds in SBR and oSBR (a) and NBR 18, NBR 32.5X and NBR 34 (b) and NBR 39 (c), compounds. Note that NBR $32.5 \mathrm{X}$ means caboxylated NBR

Table 3 Curing parameters of the tested compounds

\begin{tabular}{|c|c|c|c|c|c|c|c|c|c|c|c|c|c|}
\hline 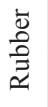 & $\begin{array}{l}\text { CBT content } \\
{[\mathrm{phr}]}\end{array}$ & $\begin{array}{l}\mathrm{M}_{\mathrm{L}} \\
{[\mathrm{dNm}]}\end{array}$ & $\begin{array}{l}\mathrm{M}_{\mathrm{H}} \\
{[\mathrm{dNm}]}\end{array}$ & $\begin{array}{l}\mathrm{t}_{0.1} \\
{[\mathrm{~min}]}\end{array}$ & $\begin{array}{l}\mathrm{t}_{0.5} \\
{[\mathrm{~min}]}\end{array}$ & $\begin{array}{l}\mathrm{t}_{0.9} \\
{[\mathrm{~min}]}\end{array}$ & 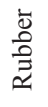 & $\begin{array}{l}\text { CBT content } \\
{[\mathrm{phr}]}\end{array}$ & $\begin{array}{l}\mathrm{M}_{\mathrm{L}} \\
{[\mathrm{dNm}]}\end{array}$ & $\begin{array}{l}\mathrm{M}_{\mathrm{H}} \\
{[\mathrm{dNm}]}\end{array}$ & $\begin{array}{l}\mathrm{t}_{0.1} \\
{[\mathrm{~min}]}\end{array}$ & $\begin{array}{l}\mathrm{t}_{0.5} \\
{[\mathrm{~min}]}\end{array}$ & $\begin{array}{l}\mathrm{t}_{0.9} \\
{[\mathrm{~min}]}\end{array}$ \\
\hline \multirow{6}{*}{$\frac{\widetilde{v}}{\mathscr{n}}$} & 0 & 3.16 & 22.50 & 6.68 & 9.01 & 12.37 & \multirow{2}{*}{$\begin{array}{l}\stackrel{\infty}{\widetilde{a}} \\
\stackrel{\tilde{z}}{z}\end{array}$} & 0 & 3.69 & 30.40 & 2.74 & 3.41 & 4.23 \\
\hline & 10 & 2.49 & 14.96 & 6.11 & 8.51 & 12.41 & & 20 & 2.95 & 22.99 & 2.90 & 3.45 & 4.57 \\
\hline & 20 & 1.62 & 8.21 & 5.67 & 7.01 & 12.56 & \multirow{2}{*}{$\begin{array}{l}x \\
n \\
\sim \\
m \\
\sim \\
\tilde{n} \\
z\end{array}$} & 0 & 5.23 & 31.60 & 5.89 & 6.81 & 9.54 \\
\hline & 30 & 1.42 & 5.81 & 5.27 & 7.41 & 12.51 & & 20 & 3.02 & 24.22 & 6.61 & 7.49 & 10.09 \\
\hline & 40 & 1.43 & 4.88 & 5.30 & 6.94 & 13.20 & \multirow{2}{*}{$\begin{array}{l}\stackrel{\sim}{m} \\
\stackrel{a}{n} \\
\vec{z}\end{array}$} & 0 & 2.62 & 32.41 & 2.76 & 3.15 & 4.60 \\
\hline & 50 & 1.37 & 3.92 & 5.21 & 6.66 & 13.30 & & 20 & 1.94 & 24.22 & 3.12 & 3.58 & 5.76 \\
\hline \multirow{6}{*}{ 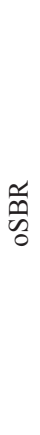 } & 0 & 3.75 & 15.54 & 6.16 & 8.32 & 10.23 & \multirow{6}{*}{$\begin{array}{l}\text { r } \\
\stackrel{n}{n} \\
\text { z }\end{array}$} & 0 & 2.68 & 33.82 & 2.21 & 2.71 & 6.71 \\
\hline & 10 & 3.16 & 13.65 & 6.11 & 8.74 & 11.13 & & 10 & 2.08 & 29.60 & 2.44 & 3.05 & 8.17 \\
\hline & 20 & 2.72 & 9.56 & 5.99 & 8.39 & 10.23 & & 20 & 2.12 & 25.99 & 3.01 & 3.71 & 9.52 \\
\hline & 30 & 1.85 & 5.58 & 5.75 & 8.27 & 11.01 & & 30 & 1.59 & 23.10 & 2.64 & 3.39 & 9.31 \\
\hline & 40 & 1.51 & 3.77 & 5.41 & 7.97 & 11.51 & & 40 & 1.28 & 20.30 & 2.80 & 3.53 & 11.07 \\
\hline & 50 & 1.18 & 3.11 & 5.24 & 7.37 & 11.64 & & 50 & 1.28 & 18.66 & 3.04 & 3.93 & 11.08 \\
\hline
\end{tabular}




\subsection{Morphology}

Inspecting the fracture surface, it can be clearly seen that CBT crystallized upon cooling in each compound and formed a separated second phase (Figs. 2 and 3). This is in concordance with the findings in References [14-17]. The shape of the CBT phase changed as a function of rubber type (as reported in Reference [17]), and in case of NBR also as a function of its AN content. In SBR and oSBR compounds CBT formed relatively large agglomerates with dimensions of $50-100 \mu \mathrm{m}$, or larger. Under tensile load, the adhesion between these agglomerates cracked and separated from the matrix.

Based on the fracture surfaces it can be clearly stated, that NBR based compounds showed obviously better compatibility with CBT. Dispersion of the CBT particles improved with increasing AN content of the NBR rubber (Fig. 2). CBT showed significantly better adhesion to NBR matrices than SBR and oSBR, markedly less separation of the CBT particles from the rubber matrix was observed under tensile load. A deeper insight into CBT phase reveals that plate like crystals can be found in oSBR, SBR and NBR compounds. In SBR and oSBR this crystalline structure appears inside the $\mathrm{CBT}$ agglomerates (Fig. 3/a), while in NBR compounds this plate (and prismatic) like shape is more developed and pronounced (Fig. 3/b and c). With increasing AN content of the NBR small, finely dispersed CBT crystals replaced the agglomerated structures. Higher AN content means higher polarity of the rubber, therefore a connection between the polarity and the CBT phase dispersion can be assumed which obviously supports the CBT dispersion in the corresponding NBR.

\subsection{Mechanical properties}

Tensile mechanical properties are summarized in Fig. 4-6, whereas the tear strength and hardness values are listed in Table 2 .

CBT had a positive effect on the tensile strength and elongation at break values of SBR and oSBR compounds, though in oSBR compounds above $20 \mathrm{phr}$ CBT content a setback can be seen in both tensile strength and elongation at break. In SBR based compounds this decrement is not so pronounced as for oSBR compound, however, a modest drop can be observed between 20 and $30 \mathrm{phr}$ CBT in tensile strength. The same tendency can be seen in tear strength values (Table 4) of these compounds. Hardness values of the SBR and oSBR compounds increased with increasing CBT content both in SBR and oSBR matrices. Studying the effect of CBT on NBR compounds (Fig. 6 and 7), one can see a significant improvement in both tensile strength and elongation at break values of all tested systems. On the other hand, the moduli at $100 \%$ and $300 \%$ deformations (M100 and M300) remained unchanged. This suggest that CBT has only a little effect at modest deformations, however, is able to successfully hamper final failure. Carboxylation of NBR has no significant effect on the mechanical properties of the CBT-containing NBR compounds. Studying NBR with highest AN content (namely $39 \mathrm{~m} \%$ ) as a function of CBT content (0-50 phr), it was found, that CBT definitely has a reinforcing effect on this rubber in the full range of the studied CBT content. Note that, however, at $50 \mathrm{phr}$ CBT content a small deterioration can be seen in the elongation at break (Fig. 6a).

Tear strength values increased in the presence of CBT similarly to tensile strength values. Hardness of NBR compounds showed less increment, than SBR and oSBR based ones.

Results confirmed our expectations, mechanical properties of all investigated rubber compounds could be improved by CBT. Higher polarity of the base rubber (higher AN content) led to finer dispersion of CBT particles, and better rubber-CBT adhesion, which could be observed in improving mechanical properties.

Results of DMTA measurements are depicted in Fig. 7 and Table 5. Apparent crosslink density values were calculated using the plateau moduli of the rubbers. According to the rubber elasticity theory, the inverse of the plateau modulus $\left(\mathrm{E}_{\mathrm{pl}}\right)$ at temperatures above the glass transition temperature $\left(\mathrm{T}_{\mathrm{g}}\right)$ correlates with the mean molecular mass between the crosslinks $\left(\mathrm{M}_{\mathrm{c}},[\mathrm{g} / \mathrm{mol}]\right)$ :

$$
M_{c}=\frac{3 \rho R T}{E_{p l}}
$$

where $\rho$ is the density $\left[\mathrm{kg} / \mathrm{m}^{3}\right], \mathrm{R}$ is the universal gas constant $[8.314 \mathrm{~J} / \mathrm{Kmol}], \mathrm{T}$ is the absolute temperature $[\mathrm{K}]$, $(\mathrm{T}=293 \mathrm{~K}), \mathrm{E}_{\mathrm{pl}}$ is the plateau modulus [Pa].

The apparent crosslink density:

$$
v_{c}=\frac{\rho}{M_{c}}=\frac{E_{p l}}{3 R T}
$$

where $v_{c}$ is the apparent crosslink density $\left[\mathrm{mol} / \mathrm{m}^{3}\right]$.

It has to be emphasized that $v_{\mathrm{c}}$ is only an apparent value, reflecting also the various interactions between the rubber matrix and the fillers (CBT in this case), not only the chemical crosslinking of the matrix.

It can be clearly seen, that $v_{c}$ increases with added CBT for each tested rubber at room temperature $(\mathrm{T}=293 \mathrm{~K})$. Results show that in NBR based compounds this effect tends to be more pronounced if the AN content of the base rubber increases, so the interaction between the rubber matrix and CBT phase strengthens with increasing CBT content. Maximum values of the loss factor decreased in all compounds, and the peaks were shifted to higher temperatures, therefore it can be stated, that molecular segment mobility was hindered by CBT. In SBR based compounds with $50 \mathrm{phr}$ CBT, a second peak was observed at $35.2^{\circ} \mathrm{C}$ in the $\tan \delta$ trace, with a significant drop in the storage modulus trace. Similar phenomenon could be seen in the oSBR+50CBT compound, but less pronouncedly. 


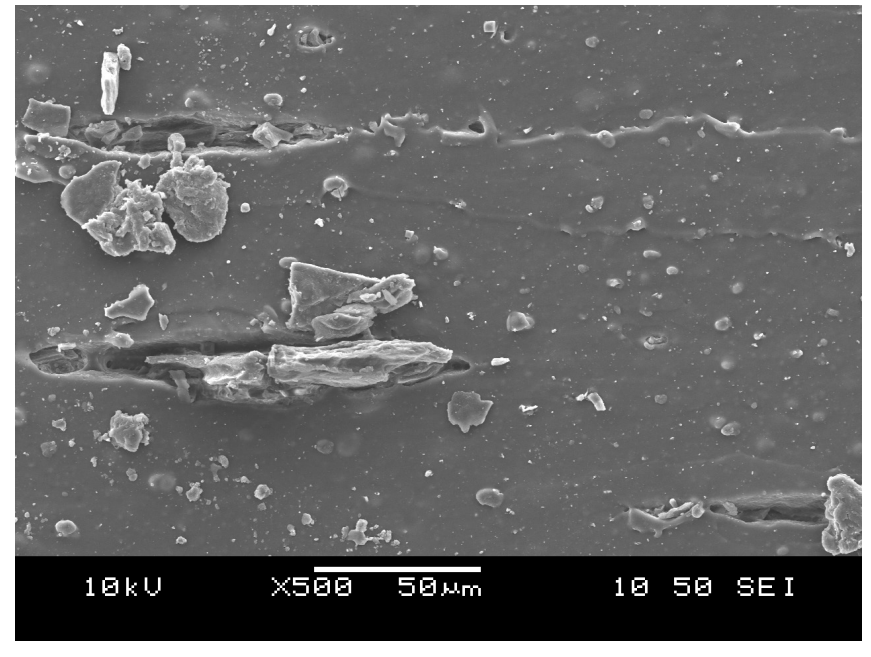

a)

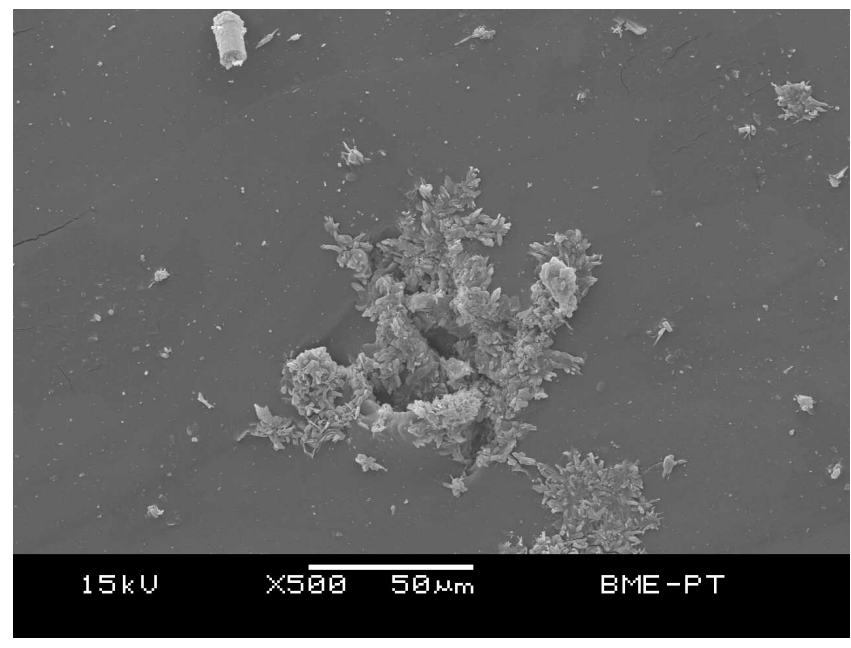

c)

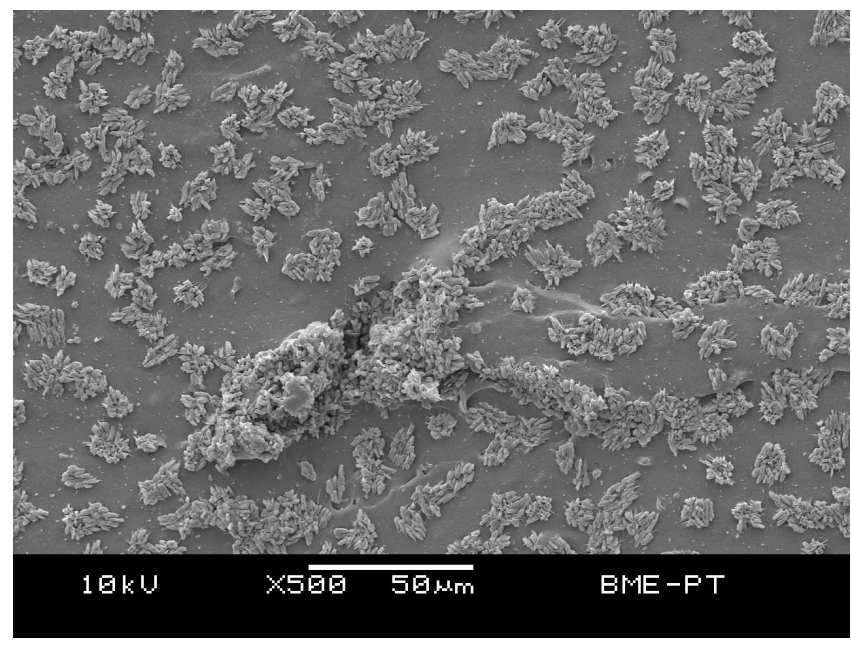

e)

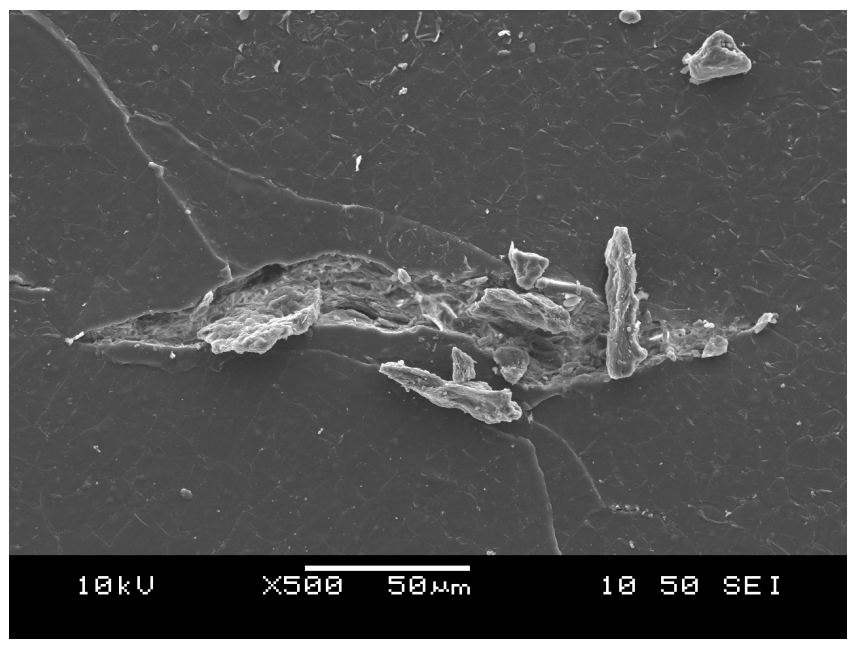

b)

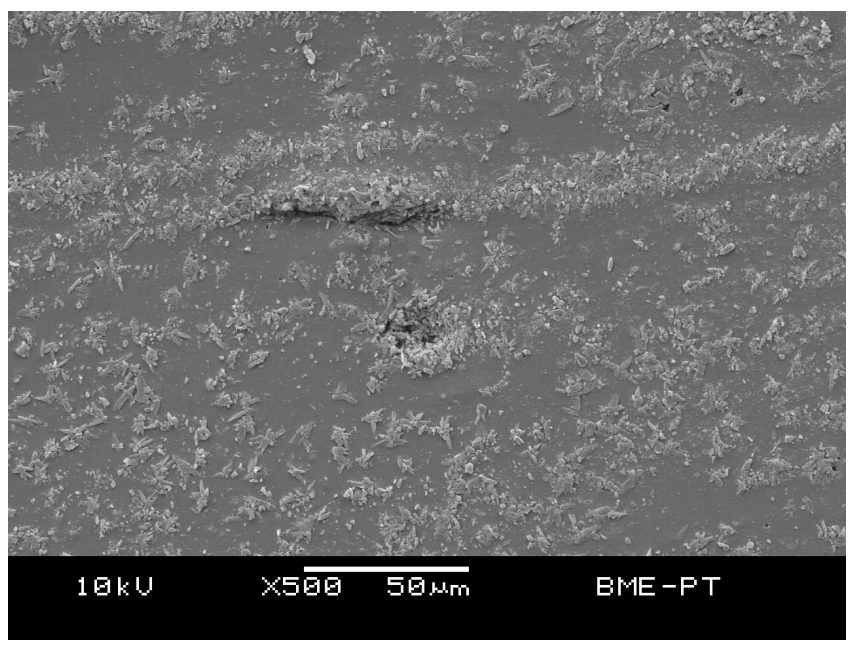

d)

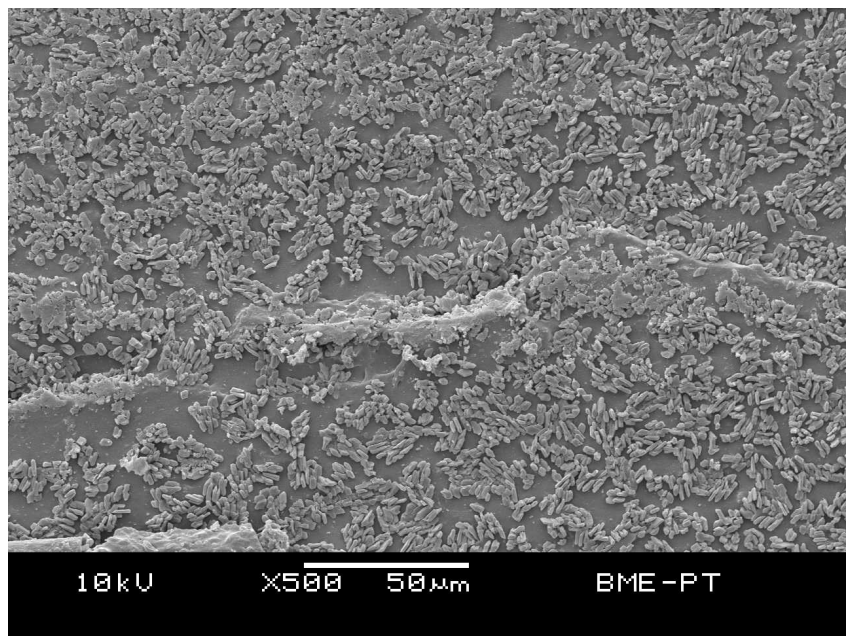

f)

Fig. 2 Tensile fracture surfaces of SBR (a), oSBR (b), NBR 18 (c), NBR 32.5X (d), NBR 34 (e) and NBR 39 compound with 20 phr CBT 


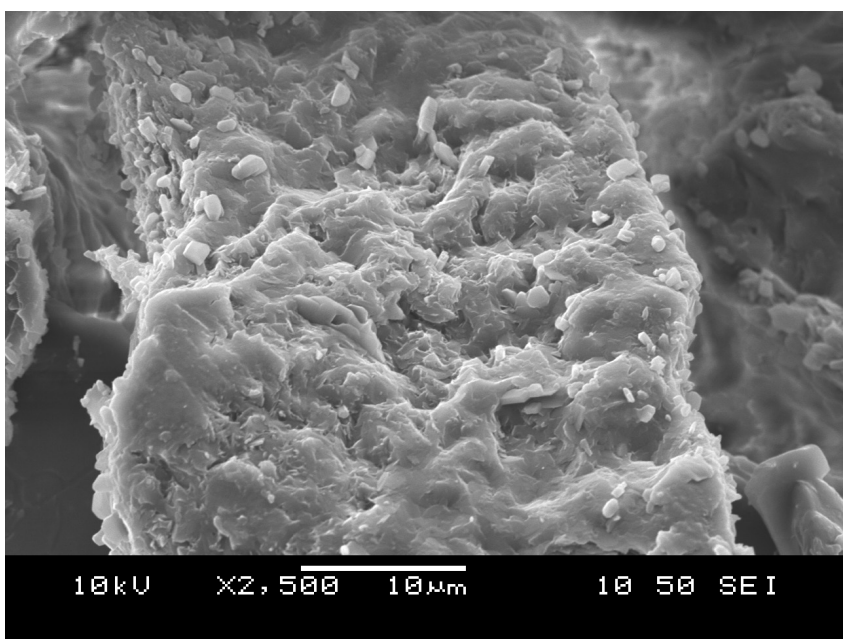

a)

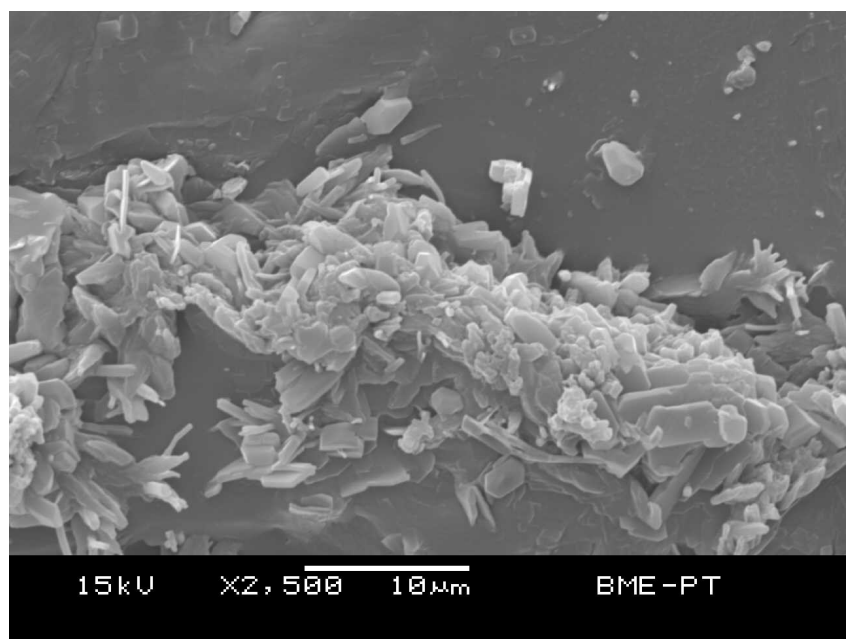

b)

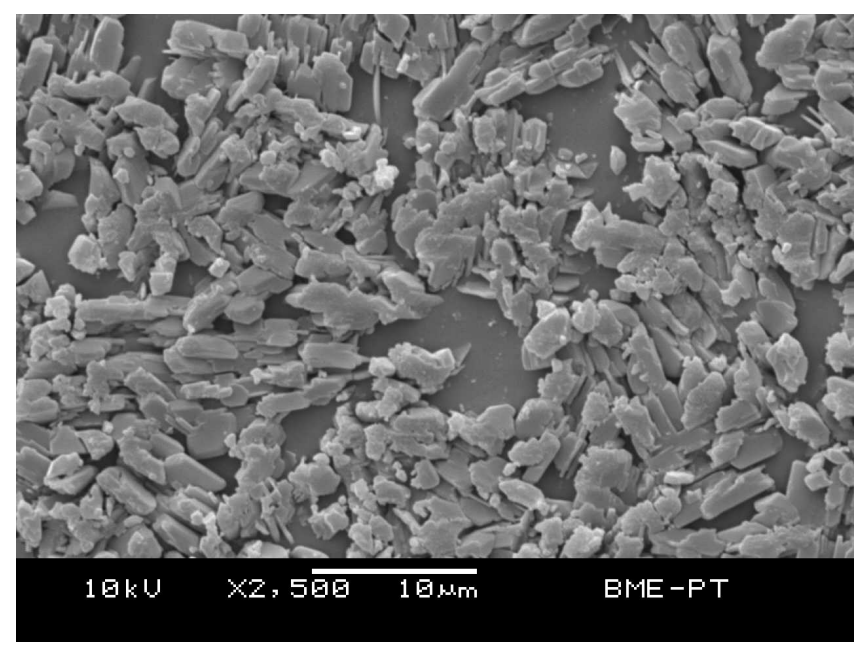

c)

Fig. 3 Fracture surface of the 20 phr CBT containing SBR (a) NBR 18 (b) and NBR 39 (c) tensile specimen at higher magnification
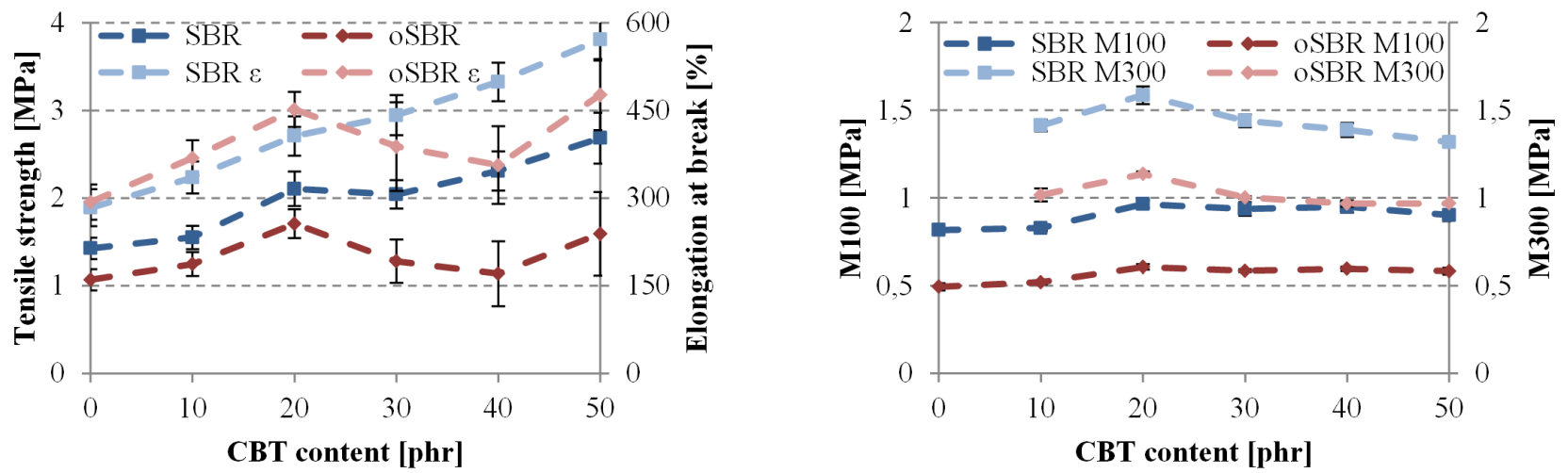

Fig. 4 Tensile properties of the tested SBR and oSBR rubbers (M100 and M300 represents the stress values measured at elongations of 100 and $300 \%$, respectively) 

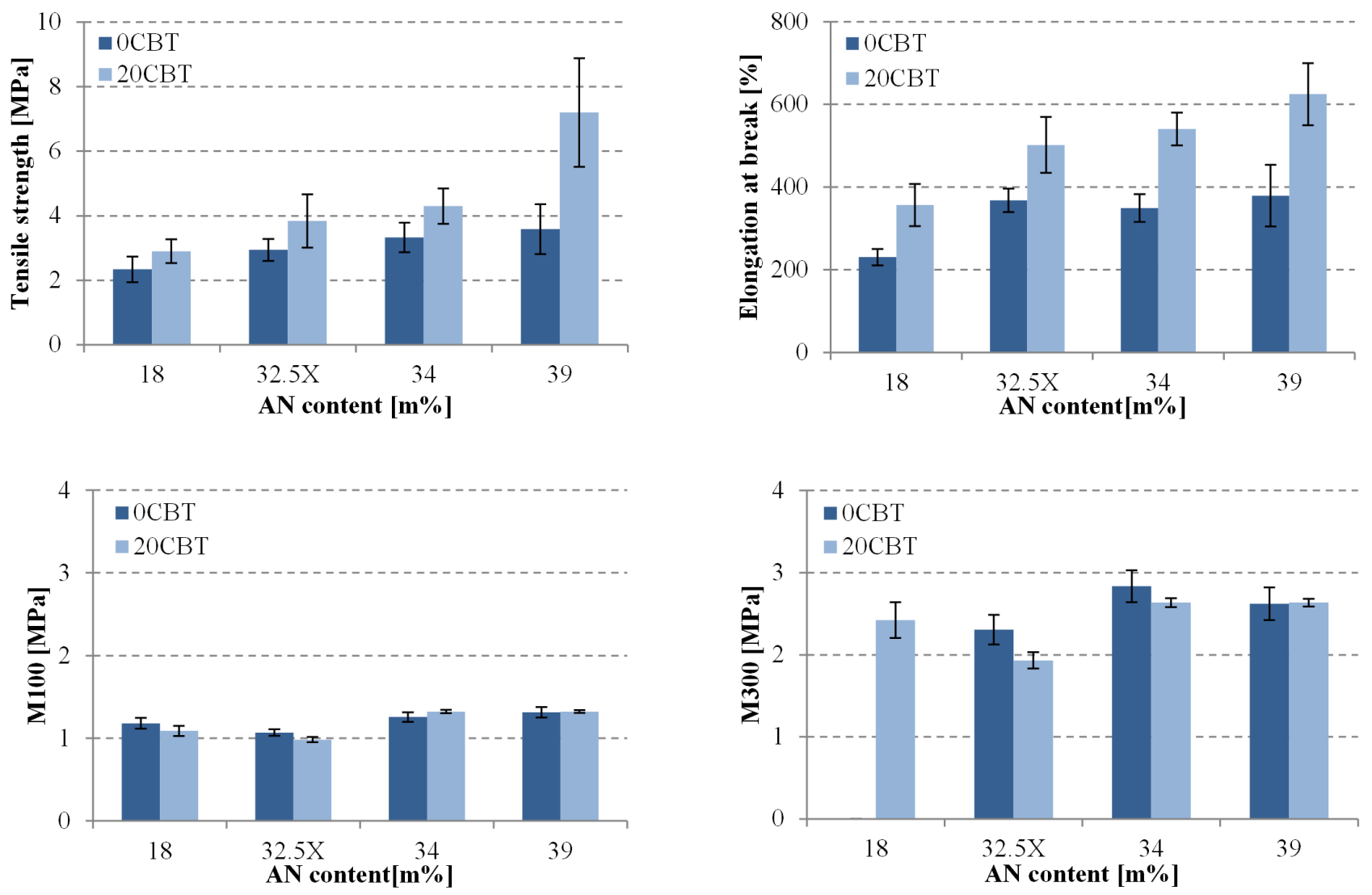

Fig. 5 Tensile properties of the tested NBR and XNBR (32.5X) rubbers (M100 and M300 represents the stress values measured at elongations of 100 and $300 \%$, respectively)

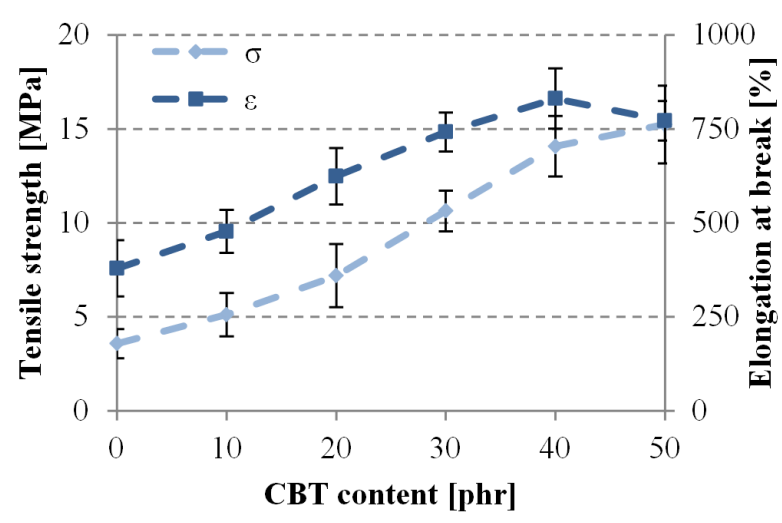

a)

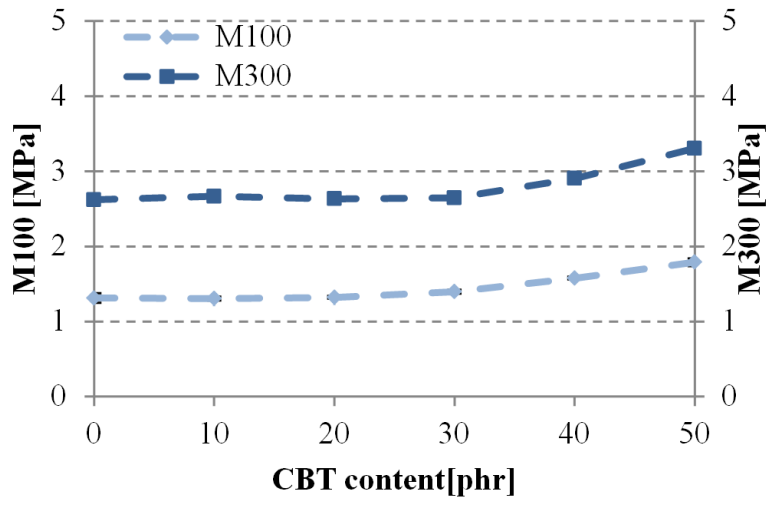

b)

Fig. 6 Tensile properties of the NBR rubber with 39 m\% AN content (M100 and M300 represents the stress values measured at elongations of 100 and $300 \%$, respectively)

\subsection{Oil resistance}

Weight changes of the compounds during the oil resistance tests are summarized in Fig. 8.

In line with the expectations, mass changes of the compounds markedly decreased with increasing $\mathrm{AN}$ content of the base rubber (note that decreasing change in mass represents increasing oil resistance). The addition of CBT further improved oil resistance, but this effect got less noticeable with increasing AN content (due to the initially good oil resistance of the rubbers). 
Table 4 Tear strength and hardness values of the tested rubbers

\begin{tabular}{|c|c|c|c|c|c|c|c|}
\hline \multirow{2}{*}{$\begin{array}{l}\dot{\bar{D}} \\
\frac{0}{3} \\
\stackrel{1}{1}\end{array}$} & \multirow{2}{*}{$\begin{array}{l}\text { CBT content } \\
{[\mathrm{phr}]}\end{array}$} & Tear strength & Hardness & \multirow{2}{*}{ 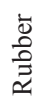 } & CBT content & Tear strength & Hardness \\
\hline & & {$[\mathrm{kN} / \mathrm{m}]$} & {$\left[\mathrm{Sh} \mathrm{A}^{\circ}\right]$} & & {$[\mathrm{phr}]$} & {$[\mathrm{kN} / \mathrm{m}]$} & {$\left[\mathrm{Sh} \mathrm{A}^{\circ}\right]$} \\
\hline \multirow{6}{*}{ 品 } & 0 & $6.94 \pm 1.46$ & $44.3 \pm 0.5$ & $\infty$ & 0 & $7.34 \pm 0.83$ & $50.2 \pm 0.9$ \\
\hline & 10 & $8.29 \pm 1.13$ & $47.1 \pm 0.3$ & $\vec{z}$ & 20 & $10.94 \pm 1.42$ & $52.8 \pm 0.9$ \\
\hline & 20 & $10.84 \pm 0.83$ & $50.6 \pm 0.5$ & 离 & 0 & $9.99 \pm 0.74$ & $50.3 \pm 0.3$ \\
\hline & 30 & $10.82 \pm 1.04$ & $55.1 \pm 0.9$ & 受 & 20 & $12.82 \pm 0.65$ & $51.9 \pm 0.4$ \\
\hline & 40 & $12.46 \pm 0.49$ & $57.1 \pm 1.3$ & ষ্ & 0 & $8.62 \pm 0.65$ & $53.7 \pm 0.6$ \\
\hline & 50 & $12.95 \pm 1.07$ & $61.0 \pm 1.0$ & 乙 & 20 & $12.01 \pm 1.39$ & $54.2 \pm 0.5$ \\
\hline \multirow{6}{*}{$\frac{\widetilde{0}}{0}$} & 0 & $4.67 \pm 0.88$ & $29.6 \pm 1.1$ & \multirow{6}{*}{$\frac{\partial}{\hat{\vartheta}}$} & 0 & $9.84 \pm 1.28$ & $54.1 \pm 0.4$ \\
\hline & 10 & $5.71 \pm 0.42$ & $32.6 \pm 0.2$ & & 10 & $10.72 \pm 0.70$ & $54.2 \pm 0.2$ \\
\hline & 20 & $7.62 \pm 0.61$ & $35.9 \pm 0.6$ & & 20 & $13.15 \pm 1.13$ & $55.6 \pm 0.2$ \\
\hline & 30 & $7.36 \pm 0.66$ & $39.8 \pm 0.6$ & & 30 & $15.92 \pm 1.34$ & $59.5 \pm 0.6$ \\
\hline & 40 & $7.67 \pm 1.81$ & $42.3 \pm 0.9$ & & 40 & $21.24 \pm 1.13$ & $63.6 \pm 0.3$ \\
\hline & 50 & $8.43 \pm 0.47$ & $44.9 \pm 0.3$ & & 50 & $24.12 \pm 1.42$ & $67.9 \pm 0.5$ \\
\hline
\end{tabular}

Table 5 Moduli, apparent crosslink densities, maximal tan $\delta$ values and glass transition temperatures of the tested rubbers derived from DMTA

\begin{tabular}{|c|c|c|c|c|c|}
\hline \multirow{2}{*}{ 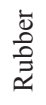 } & CBT content & $\mathrm{E}_{\mathrm{pl}}$ & $v_{\mathrm{c}}$ & $\tan \delta_{\text {max }}$ & $\mathrm{T}_{\mathrm{g}}$ \\
\hline & {$[\mathrm{phr}]$} & {$[\mathrm{MPa}]$} & {$\left[\mathrm{mol} / \mathrm{m}^{3}\right]$} & {$[-]$} & {$\left[{ }^{\circ} \mathrm{C}\right]$} \\
\hline \multirow{2}{*}{$\frac{\mathscr{v}}{\mathscr{m}}$} & 0 & 2.69 & 368 & 1.93 & -30.2 \\
\hline & 50 & 13.88 & 1899 & 0.92 & -28.7 \\
\hline \multirow{2}{*}{$\begin{array}{l}\frac{1}{0} \\
\text { : } \\
0\end{array}$} & 0 & 1.27 & 173 & 1.56 & -15.1 \\
\hline & 50 & 10.46 & 1431 & 0.73 & -10.3 \\
\hline \multirow{2}{*}{ 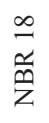 } & 0 & 2.96 & 404 & 1.25 & -27.7 \\
\hline & 20 & 7.09 & 970 & 0.83 & -25.5 \\
\hline \multirow{2}{*}{ 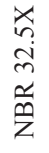 } & 0 & 3.65 & 499 & 1.70 & -8.4 \\
\hline & 20 & 8.08 & 1105 & 1.20 & -5.5 \\
\hline \multirow{2}{*}{$\begin{array}{l}\stackrel{+}{c} \\
\text { c } \\
\text { Z }\end{array}$} & 0 & 4.02 & 550 & 1.89 & -5.8 \\
\hline & 20 & 9.21 & 1260 & 1.26 & -1.2 \\
\hline \multirow{2}{*}{ 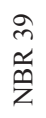 } & 0 & 5.80 & 793 & 1.89 & 1.0 \\
\hline & 50 & 37.10 & 5076 & 0.77 & 4.6 \\
\hline
\end{tabular}




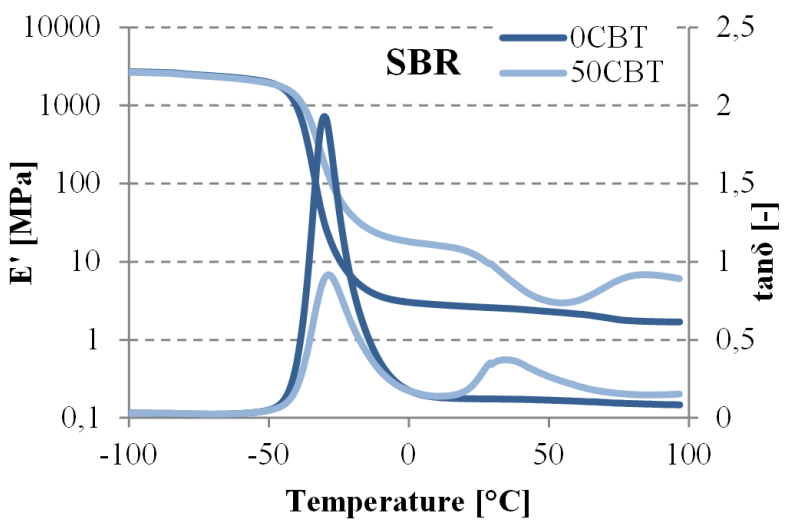

a)

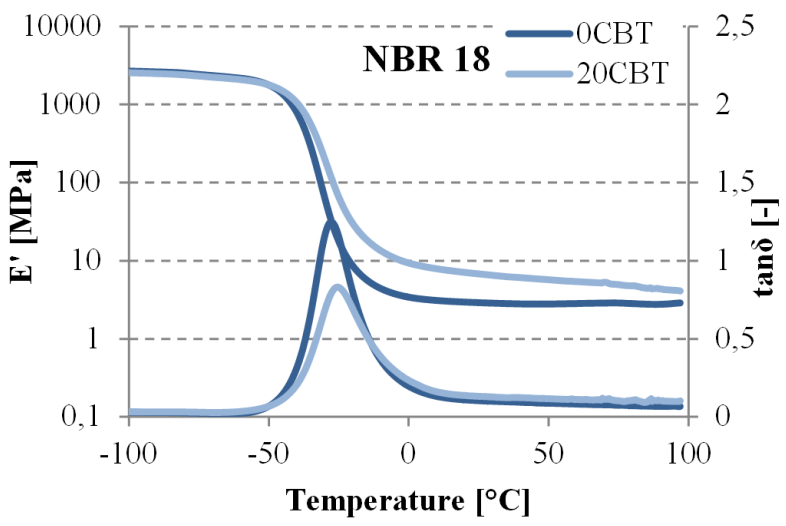

c)

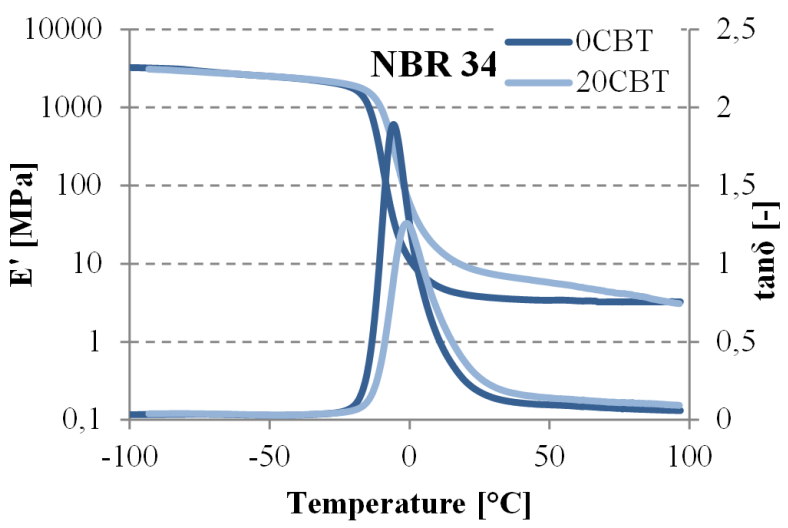

e)

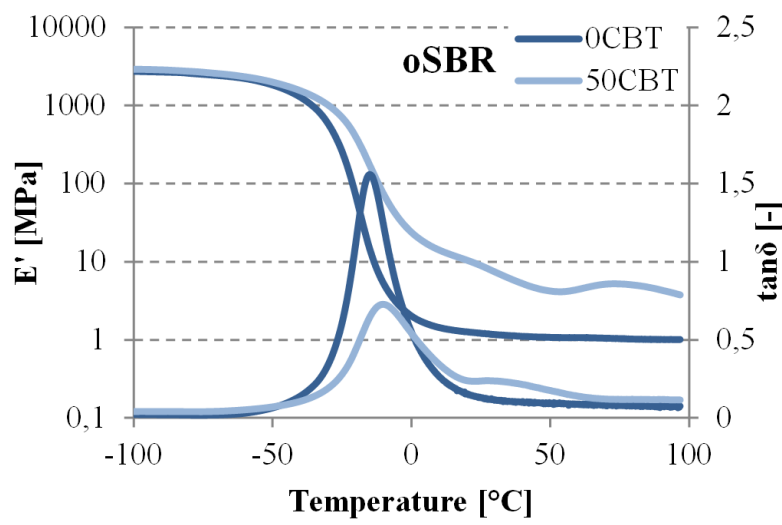

b)

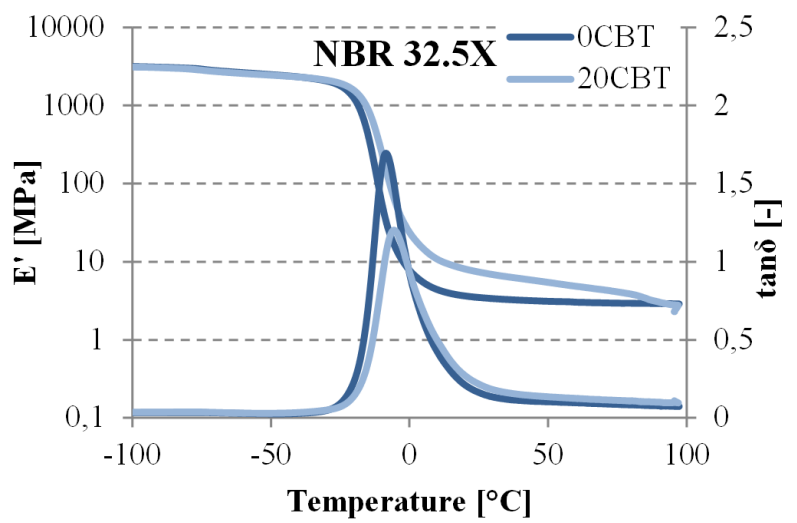

d)

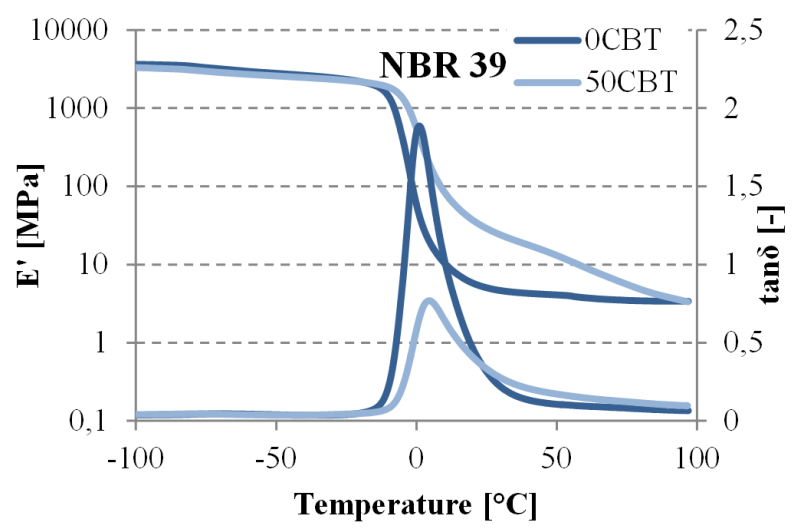

f)

Fig. 7 E' vs. temperature and tan $\delta$ vs. temperature traces of the tested compounds (note that at SBR, oSBR and NBR 39 compounds, the CBT content is 0 and $50 \mathrm{phr}$, not 0 and 20 as at the others)

\section{Conclusion}

Based on the results the following conclusions can be drawn:

- $\quad$ CBT effectively decreased the viscosities of all studied uncured compounds, therefore it can improve the processability of these rubber mixes above the melting temperatures of the oligomer.

- Curing time $\left(\mathrm{t}_{0.9}\right)$ was slightly delayed in all tested rubbers, however, the induction phase of curing of SBR and oSBR compounds found to be marginally shorter in the presence of CBT.

- Considerable reinforcing effect of CBT could be observed for all tested rubbers. This manifested in increasing tensile and tear strength, and also in enhanced elongation at break values.

- Dispersion of the CBT particles became finer and their adhesion to the rubber matrix enhanced with increasing polarity of the rubber.

- Oil resistance of the NBR based compounds can be further improved by CBT.

\section{Acknowledgement}

This work was supported by OTKA Hungarian Scientific Research Fund by grants (K100294) in Hungary. 


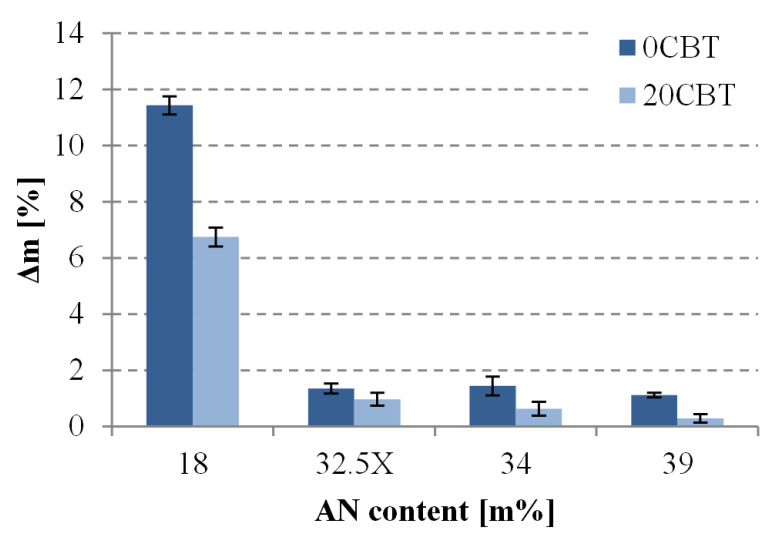

a)

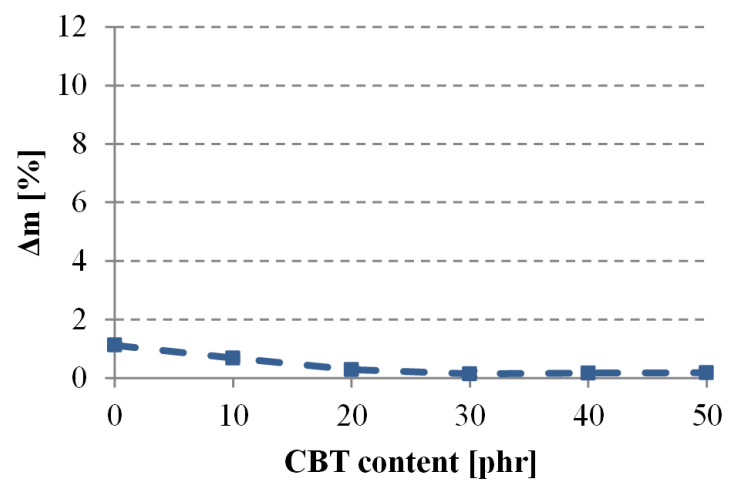

b)

Fig. 8 Change in mass after a 70 hours long immersion in ASTM no. 3 oil of NBR 18, NBR 32.5X and NBR 34 (a) and NBR 39 (b), compounds. Note that NBR $32.5 X$ means the carboxylated NBR

\section{References}

[1] Mohd Ishak, Z. A., Gatos, K. G., Karger-Kocsis, J. "On the in-situ polymerization of cyclic butylene terephthalate oligomers: DSC and rheological studies." Polymer Engineering and Science. 46(6), pp. 743-750. 2006. https://doi.org/10.1002/pen.20486

[2] Mohd Ishak, Z. A., Shang, P. P., Karger-Kocsis, J. "A modulated DSC study on the in situ polymerization of cyclic butylene terephthalate oligomers." Journal of Thermal Analysis and Calorimetry. 84(3), pp. 637-641. 2006. https://doi.org/10.1007/s10973-005-7059-Z

[3] Mohd Ishak, Z. A., Leong, Y. W., Steeg, M., Karger-Kocsis, J. "Mechanical properties of woven glass fabric reinforced in situ polymerized poly(butylene terephthalate) composites." Composites Science and Technology. 67(3-4), pp. 390-398. 2007.

https://doi.org/10.1016/j.compscitech.2006.09.012

[4] Parton, H., Baets, J., Lipnik, P., Goderis, B., Devaux, J., Verpoest, I. "Properties of poly(butylene terephthatlate) polymerized from cyclic oligomers and its composites." Polymer. 46(23), pp. 9871-9880. 2005. https://doi.org/10.1016/j.polymer.2005.07.082

[5] Jiang, Z., Siengchin, S., Zhou, L.-M., Steeg, M., Karger-Kocsis, J., Man „H. C. "Poly (butylene terephthalate)/silica nanocomposites prepared from cyclic butylene terephthalate." Composites Part A-Applied Science and Manufacturing. 40(3), pp. 273-278. 2009.

https://doi.org/10.1016/j.compositesa.2008.12.003

[6] Tripathy, A. R., Burgaz, E., Kukureka, S. N., MacKnight, W. J. "Poly(butylene terephthalate) nanocomposites prepared by in-situ polymerization." Macromolecules. 36(23), pp. 8593-8595. 2003. https://doi.org/10.1021/ma021364+

[7] Tripathy A. R. , MacKnight W. J., Kukureka S. N. "In-situ copolymerization of cyclic poly(butylene terephthalate) oligomers and $\varepsilon$-caprolactone." Macromolecules. 37(18), pp. 6793-6800. 2004. https://doi.org/10.1021/ma0400517

[8] Baets, J., Godara, A., Devaux, J., Verpoest, I. "Toughening of isothermally polymerized cyclic butylene terephthalate for use in composites." Polymer Degradation and Stability. 95(3), pp. 346-352. 2010. https://doi.org/10.1016/j.polymdegradstab.2009.11.005

[9] Abt, T., Sanchez-Soto, M., Martinez de Ilarduya, A. "Toughening of in situ polymerized cyclic butylene terephthalate by chain extension with a bifunctional epoxy resin." European Polymer Journal. 48(1), pp. 163-171. 2012. https://doi.org/10.1016/j.eurpolymj.2011.10.017
[10] Abt, T., Bou, J. J., Sanchez-Soto, M. "Isocyanate toughening of pCBT/ organoclay nanocomposites with exfoliated structure and enhanced mechanical properties." Express Polymer Letters. 8(12), pp. 953-966. 2014. https://doi.org/10.3144/expresspolymlett.2014.96

[11] Abt, T., Martinez de Ilarduya, A., Bou, J. J., Sanchez-Soto, M. "Isocyanate toughened pCBT: Reactive blending and tensile properties." Express Polymer Letters. 7(2), pp. 172-185. 2013. https://doi.org/10.3144/expresspolymlett.2013.16

[12] Rösch, M. "Verarbeitungshilfsmittel: Alles im Fluss." (Processing Aid: It's All a Matter of Flow.) Kunststoffe. 96, pp. 90-91. 2006. (in German)

[13] Tzounis, L., Gaertner, T., Liebscher, M., Poetschke, P., Stamm, M., Voit, B., Heinrich, G. "Influence of a cyclic butylene terephthalate oligomer on the processability and thermoelectric properties of polycarbonate/ MWCNT nanocomposites." Polymer. 55(21), pp. 5381-5388. 2014. https://doi.org/10.1016/j.polymer.2014.08.048

[14] Karger-Kocsis, J., Felhos, D., Bárány, T., Czigány, T. "Hybrids of HNBR and in situ polymerizable cyclic butylene terephthalate (CBT) oligomers: properties and dry sliding behavior." Express Polymer Letters. 2(7), pp. 520-527. 2008.

https://doi.org/10.3144/expresspolymlett.2008.62

[15] Xu, D., Karger-Kocsis, J. "Rolling and sliding wear properties of hybrid systems composed of uncured/cured HNBR and partly polymerized cyclic butylene terephthalate (CBT)." Tribology International. 43(1-2), pp. 289-298. 2010.

https://doi.org/10.1016/j.triboint.2009.06.008

[16] Xu, D., Karger-Kocsis, J., Apostolov, A. A. "Hybrids from HNBR and in situ polymerizable cyclic butylene terephthalate (CBT): Structure and rolling wear properties." European Polymer Journal. 45(4), pp. 12701281. 2009.

https://doi.org/10.1016/j.eurpolymj.2008.11.029

[17] Halász, I., Bárány, T. "Novel Bifunctional Additive for Rubbers: Cyclic Butylene Terephthalate Oligomer." Periodica Polytechnica Mechanical Engineering. 59(4), pp. 182-188. 2015. https://doi.org/10.3311/PPme.8321 